\title{
Resenha
}

\section{Direitos humanos dos pacientes ${ }^{1}$}

Patients human rights

Los derechos humanos de los pacientes

Denise Gonçalves de Araújo Mello e Paranhos²

O livro Direitos humanos dos Pacientes, lançado em março/2016 pela Editora Juruá, é uma obra inovadora na análise dos pacientes como titulares de direitos.

Sua autora, Aline Albuquerque, é Pós-Doutora em Direitos Humanos e em Direito Humano à Saúde, Doutora em Ciências da Saúde, área de concentração em Bioética, Mestre em Direito e especialista em Saúde Internacional e em Bioética. Atua como Advogada da União, é Chefe da Assessoria Jurídica da Secretaria de Direitos Humanos da Presidência da República, bem como é Professora de pós-graduação em Bioética da Universidade de Brasília - Cátedra Unesco - e Professora de Direitos Humanos do Centro Universitário de Brasília. A pesquisa que deu origem a esse trabalho foi realizada na Universidade de Essex, Inglaterra, e teve como foco os direitos humanos dos pacientes, tais como o direito à privacidade, informação, não discriminação, proibição de tratamento desumano ou degradante, dentre outros relacionados à saúde.

Primeiro livro dessa natureza escrito em português, a autora chama a atenção para problemas ainda pouco conscientizados no Brasil e no mundo, tais como as violações de direitos humanos dos pacientes nas relações diárias de cuidados em saúde. Ressalta, na obra, a existência de desafios teóricos e normativos para se estabelecer os direitos dos pacientes sobre as bases dos direitos humanos. Aponta a existência de normas e jurisprudências internacionais de proteção à saúde no âmbito da Organização das Nações Unidas (ONU), do Sistema Interamericano de Direitos Humanos, do Sistema Europeu de Direitos Humanos e do Sistema Africano dos Direitos Humanos e

\footnotetext{
${ }^{1}$ Albuquerque A. Direitos Humanos dos Pacientes. Curitiba: Juruá; 2016. 287 páginas. ISBN 978-85-362-5519-4 2 Mestranda em Bioética pela Universidade de Brasília - Cátedra Unesco. Especialista em Direito Tributário pela Pontifícia Universidade Católica de Goiás. Graduada em Direito pela Universidade Federal de Goiás. Analista Judiciário da Justiça Federal - Seção Judiciária de Goiás. Goiânia - Goiás. Brasil. E-mail: paranhos.denise@uol.com.br
} 
propõe a efetiva utilização desse arcabouço teórico, normativo e institucional do Direito Internacional na temática dos cuidados em saúde dos pacientes.

Partindo da premissa de que os Direitos Humanos dos Pacientes integram o Direito Internacional dos Direitos Humanos, buscou, no livro, definir os princípios integrantes dos Direitos Humanos dos Pacientes, construir um conteúdo específico a partir da análise das regras gerais de direitos humanos e da jurisprudência internacional e, por fim, analisar modos de aplicação dos Direitos Humanos dos Pacientes.

A divisão de assuntos foi realizada de forma bastante didática e organizada em três partes, explicitadas a seguir.

Na primeira parte da obra, Albuquerque apresentou os aspectos gerais dos Direitos Humanos dos Pacientes, suas demarcações conceituais, teorias e princípios.

Iniciou por esclarecer que o paciente é um ser que deve ser enxergado sob duplo aspecto: 0 da vulnerabilidade e o da centralidade no processo de tratamento.

A fim de situar a posição do paciente frente ao conceito de Direitos Humanos, apontou que, no âmbito da ONU, tal conceito possui as seguintes características: a) os direitos humanos têm previsão legal em normas internacionais (declarações, tratados, direito costumeiro internacional, princípios gerais e outras fontes de Direito Internacional); b) seu foco é na dignidade humana; c) visa à proteção de pessoas ou grupo de pessoas, sem qualquer distinção de sexo, idade, etnia, religião, língua, país de origem etc; d) tem caráter vinculante para os Estados e demais entes estatais; e) existe uma interdependência e inter-relação das normas; f) se caracteriza, ainda, pela indivisibilidade e universalidade.

Sustenta que não se pode confundir direitos humanos e direitos fundamentais, que se distinguem nos seguintes pontos: a) em razão do conteúdo vago do primeiro, já que contido em normas internacionais, sua aplicação, no caso concreto, demanda o auxílio da jurisprudência internacional ("sentenças de Cortes Internacionais, decisões adotadas em comunicações individuais, comentários gerais e observações gerais elaborados pelos órgãos integrantes dos Sistemas ONU e Regionais de Direitos Humanos" - p. 23). Os direitos fundamentais, por sua vez, "são demarcados pela jurisprudência nacional" (p. 23); b) os direitos humanos têm conteúdo ético e jurídico, e o seu comando central é o princípio da dignidade humana; c) "a relação jurídica de direitos humanos é sempre 
entre o Estado e os indivíduos" (p. 25); d) na esfera internacional, a responsabilidade pela ofensa aos direitos humanos será sempre do Estado, e não dos indivíduos que atuam na prestação de serviços de saúde; e) é de responsabilidade do Estado editar legislação que previna e corrija a violação dos direitos humanos dos pacientes, sendo que os remédios de punição serão aqueles previstos na legislação nacional.

A autora destaca a universalidade dos direitos humanos e aponta a necessidade de se promover uma "educação afetiva" (p. 26), sob o argumento de que não basta o simples cálculo utilitarista ou a participação nas políticas públicas, pois a universalidade de direitos só se alcança quando a todos é conferido igual valor. Na esfera da saúde, em especial, todos os pacientes devem ser considerados como detentores de direitos humanos, o que os distingue de simples usuários ou consumidores.

Com relação à distinção entre paciente, usuário e consumidor, segundo a autora, o termo paciente é o mais adequado na abordagem que aqui se faz, pois implica contato humano, relação entre duas pessoas (profissionais da saúde e o doente), que é o elemento principal durante o tratamento. Daí decorre que o termo "direito do paciente" indica que "sua aplicação se dá no bojo da relação entre paciente e os profissionais da saúde" (p. 43).

Destaca que o termo usuário tem sentido diverso de paciente, pois se refere à pessoa que faz uso de um serviço, sendo com o serviço, e não com a pessoa que o presta, a sua relação. Trata-se, portanto, de uma relação impessoal.

Também ressalta que o termo consumidor não se mostra adequado, porque, além de se tratar de um conceito individualista, não abarca a noção coletiva dos sistemas de saúde. A autora enfatiza que os serviços de saúde não podem ser considerados como mercadorias. Sob a ótica dos direitos humanos, constituídos sobre bases universalistas, é defeso o acesso aos serviços de saúde com amparo apenas no autointeresse, como se fora simples relação de consumo, em razão do impacto gerado sobre recursos que devem ser distribuídos a todos, indistintamente. Por tal razão, a autora defende que "os direitos do consumidor não se aplicam aos pacientes que se encontram no âmbito do Sistema Único de Saúde, na medida em que seus serviços são de acesso universal, não demandando contrapartida financeira" (p. 45). 
A divisão de sistemas de direitos humanos foi apresentada pela autora da seguinte forma: a) Sistemas de Direitos Humanos da ONU, aplicável a todos os Estadosmembros da ONU; b) sistemas regionais: b1) Sistema Europeu de Direitos Humanos; b2) Sistema Interamericano de Direitos Humanos; b3) Sistema Africano de Direito Humanos. O papel de tais sistemas é fazer valer, na prática, as normas de direitos humanos internacionalmente reconhecidas. Salientou que Brasil se vincula aos sistemas da ONU e ao Interamericano, ou seja, responde tanto perante a Comissão Interamericana de Direitos Humanos, como também, a partir de 1998, perante a Corte Interamericana de Direitos Humanos.

A autora informou sobre a existência de uma tipologia a ser seguida pelos Estados, sob pena de violação dos direitos humanos: "de respeitar, de proteger e de realizar, que se subdivide em facilitar e prover" (p. 34). Esclareceu que as obrigações do Estado consistem no seguinte: a) o respeito consiste na obrigação do Estado em não tomar nenhuma medida capaz de obstar a plena fruição dos direitos. No campo da saúde, o Estado não pode obstar o acesso igualitário aos tratamentos médicos, impor determinadas terapêuticas, tampouco negar aos pacientes acesso às suas informações pessoais; b) a proteção diz respeito à salvaguarda do direito à saúde pelo Estado, no caso de ameaças à saúde pública por terceiros. Incumbe, portanto, ao Estado velar pela regulação normativa e administrativa dos serviços privados prestados, pela comercialização de medicamentos, bem como pelas medidas de proteção relacionadas a grupos vulneráveis; c) para a realização do direito à saúde, deve o Estado, além de criar mecanismos normativos, administrativos e políticas sanitárias que facilitem e permitam o acesso da população aos cuidados de saúde, deve promover a adequada formação profissional daqueles que trabalham na área, bem como facilitar a criação de clínicas e hospitais em números suficientes.

Ao levantar o histórico dos direitos dos pacientes, a autora ressaltou que suas conquistas foram lentas e sempre marcadas por movimentos de luta. No Brasil, apenas na década de noventa é que surgiram as primeiras normas sobre os direitos dos pacientes, mas "nunca houve a adoção de uma carta nacional dos direitos dos pacientes com força de lei" (p. 54). Além disso, em todos os movimentos reivindicatórios de direitos no Brasil, as demandas dos pacientes sempre foram marginalizadas. Com isso, 
Albuquerque informou que, embora existam normativas de direitos dos pacientes que se entrelaçam com as de direitos humanos, tais normas de direitos humanos dos pacientes se distanciam do referencial dos direitos humanos dos pacientes.

A autora enumerou várias características que diferenciam os direitos dos pacientes e os direitos humanos dos pacientes, relativamente ao campo de aplicação, abrangência, força vinculante, coercibilidade e sanções, dentre outros. Como ponto de destaque, salientou que, apesar do entrelaçamento entre eles, os direitos humanos dos pacientes derivam do princípio da dignidade humana, enquanto os direitos dos pacientes têm bases consumeristas e centradas no aspecto individual do paciente.

Outro elemento que mereceu relevo por parte da autora refere-se aos direitos humanos dos profissionais da saúde. A autora reconhece que os direitos humanos dos profissionais encontram-se intimamente relacionados com os dos pacientes, na medida em que as más condições de trabalho, os desrespeitos e perseguições ao profissional refletem em suas condutas junto ao paciente, gerando atendimentos de baixa qualidade e, consequentemente, violando direitos atinentes aos cuidados em saúde.

Ainda na primeira parte do trabalho, ao tratar dos direitos humanos dos pacientes e outros enfoques, a autora apresentou as aproximações e distanciamentos dos direitos humanos dos pacientes com a bioética, em suas dimensões teórica, institucional e normativa. Enfatizou que o referencial de humanização distancia-se dos direitos humanos dos pacientes, já que corresponde a políticas voltadas para o serviço, e não aos cuidados com o paciente. Com relação à abordagem de direitos humanos aplicados à saúde (ABDH aplicada à saúde), esclareceu que, embora ambos se ancorem no Direito Internacional dos Direitos Humanos, verifica-se uma ruptura, pois a ABDH aplicada à saúde consiste no uso de princípios de direitos humanos em políticas e programas públicos no campo sanitário, as quais não abarcam a perspectiva do paciente.

Por fim, a autora apresentou os princípios que compõem os direitos humanos dos pacientes. Antes, alertou para o fato de que estes compartilham com o direito internacional dos direitos humanos o princípio-matriz da dignidade humana, mas que, por sua especificidade, contém arcabouço principiológico próprio, integrado pelos seguintes princípios: do cuidado centrado no paciente, da autonomia relacional e da 
responsabilidade dos pacientes, os quais foram apresentados e devidamente desenvolvidos pela autora em itens próprios.

A segunda parte da obra foi dedicada ao conteúdo dos Direitos Humanos dos Pacientes, a partir de estudo da jurisprudência e da busca dos conteúdos de direitos humanos que se aplicam especificamente aos cuidados em saúde, presentes em documentos do Sistema ONU de Proteção dos Direitos Humanos, do Sistema Interamericano e do Sistema Europeu. Albuquerque esclareceu que o os Sistemas ONU e Interamericano foram utilizados porque são os sistemas a que os pacientes brasileiros podem se recorrer. Quanto ao Sistema Europeu, embora o Brasil a ele não se submeta, a autora sustentou a importância de seu estudo por ser o mais avançado dentre eles em termos de direitos humanos, de jurisprudência sobre cuidados com o paciente, bioética e consentimento informado.

A autora sublinhou a dificuldade de consenso, nos meios acadêmico e normativo, acerca de quais são os direitos que fazem parte dos direitos dos pacientes, bem como ressaltou a imbricação entre os direitos dos pacientes e os direitos humanos. A partir daí, explicitou que os direitos humanos previstos em normas internacionais e a serem abordados na segunda parte do livro seriam aqueles que se inserem no contexto dos cuidados em saúde dos pacientes, quais sejam: direito à vida; direito a não ser submetido a tortura, nem a penas ou tratamentos cruéis, desumanos ou degradantes; direito à liberdade e segurança pessoal; direito ao respeito à vida privada; direito à informação; direito de não ser discriminado; direito à saúde. A abordagem temática dos direitos foi realizada nos termos da jurisprudência internacional e estruturada da seguinte forma: a) apresentação do conteúdo geral do direito, inclusive conceitos básicos; b) conjugação de uma ou mais temáticas com casos ou documentos já tratados pela jurisprudência internacional; c) apresentação, ao final da análise de cada caso, de tabela explicativa sobre o direito humano do paciente especificamente violado, sua forma de tratamento pela jurisprudência internacional e indicação de formas de regulação e atuação do Estado para coibir a ofensa ao direito.

$\mathrm{Na}$ terceira parte do livro, a autora tratou da aplicação dos direitos humanos dos pacientes, ou seja, seus modos de concretização. Inicialmente, foi ressaltada a importância do agente do paciente como figura indispensável à efetivação dos direitos 
do paciente perante os profissionais de saúde. Segundo a autora, a primeira dificuldade em se entender a posição do agente começa com a tradução do termo em inglês "patient advocate" para o português. O agente não é um defensor (no Brasil existe a figura do Defensor Público), tampouco alguém que substitui a vontade do paciente. Trata-se de um colaborador que, juntamente como o profissional da saúde e o paciente, os três colocados em situação equânime, auxilia na condução do tratamento, solicitando informações, informando o paciente, acompanhando os procedimentos e tratamentos, ajudando o paciente a exercer sua autonomia e a fazer valer suas decisões. $O$ agente do paciente não precisa ter formação específica no campo da saúde. Pode ser um familiar, um amigo próximo, um profissional da saúde, um advogado ou alguém contratado para tal finalidade. O que se espera é que seja alguém leal ao paciente e com intuito de ajudar concretamente, a partir de diretivas antecipadas. Albuquerque examinou o papel do agente do paciente em situações diversas, tais como: o agente do paciente no hospital; em situações de emergência; no consultório médico; em relação a pacientes com transtorno mental; idosos; pessoa com deficiência intelectual; criança e adolescente. A autora informou que, diferentemente dos Estados Unidos, não há no Brasil legislação que preveja a figura do agente do paciente e salientou sua importância na concretização dos direitos humanos na esfera da saúde.

Em seguida, foi trazido à tona pela autora a experiência normativa do Reino Unido na concretização dos direitos humanos dos pacientes. A autora informou que a opção pelo modelo do Reino Unido se deu por sua similaridade com o Sistema Único de Saúde brasileiro, bem como em razão da riqueza da experiência britânica em lidar com a temática dos cuidados em saúde. Esclareceu que as diretrizes britânicas encontram-se expressas em quatro normas: a Carta de direitos dos pacientes, a Constituição do National Health Service, a Lei de Direitos Humanos de 1998 e a Lei dos Direitos e Responsabilidades dos Pacientes da Escócia, de 2011. A autora analisou, com profundidade, aspectos positivos e negativos da legislação referida.

Por fim, procedeu-se a um levantamento das normas sobre direitos humanos dos pacientes no Brasil, tanto nacionais quanto estaduais, e constatou-se que, infelizmente, o país não conta com legislação sólida que ampare tais direitos. A autora analisou a Carta dos Direitos dos Usuários do SUS, adotada pelo Ministério da Saúde em 2009, 
assim como as leis de alguns Estados, todas elas com diretrizes gerais, algumas ambivalentes e de difícil aplicação, e voltadas aos direitos dos usuários dos serviços de saúde, e não ao paciente.

Conforme se vê, o livro de Aline Albuquerque é uma obra de fôlego, que traz à tona um assunto novo, pouco familiarizado no Brasil e no mundo, merecedor de total atenção, pois atinente a um dos bens mais preciosos da humanidade: o direito à saúde.

O livro Direitos Humanos dos Pacientes possui o mérito de apontar o vazio legislativo, a falta de institucionalização na promoção e defesa dos direitos dos pacientes, bem como de contribuir para a solidificação dos direitos. O primeiro passo foi dado. Agora, cabe-nos, com fundamento na cultura de direitos humanos assinalada pela autora, lutar pela instituição de normas e pela criação de políticas públicas de proteção às pessoas que se encontram na vulnerável condição de paciente.

Recebido em 2/5/2016 Aprovado em 18/6/2016

\section{Como citar este artigo:}

Paranhos DGAM. Direitos humanos dos pacientes. Revista Cadernos Ibero-Americanos de Direito Sanitário. 2016 abr./jun, 5(2):185-192. 